\title{
HETEOROGENEIDADE ESTRUTURAL DA INDÚSTRIA DO ESTADO DE SANTA CATARINA: ALGUMAS EVIDÊNCIAS EMPÍRICAS
}

\author{
Carolina Silvestre Cândido' \\ Silvio A. F. Cario ${ }^{2}$ \\ Henrique Cavalieri da Silva ${ }^{3}$
}

\begin{abstract}
Resumo
Este trabalho tem por objetivo estudar a heterogeneidade estrutural brasileira e catarinense com o propósito de contribuir com estudos sobre a realidade econômica catarinense. A teoria economia apresenta a heterogeneidade estrutural como fruto da geração e difusão desiguais do progresso técnico. Está se expressa na brecha produtiva interna onde coexistem, em uma mesma estrutura produtiva, estratos produtivos desenvolvidos e com níveis elevados de produtividade do trabalho e estratos produtivos arcaicos com produtividade de trabalho reduzida. Através da análise do período de 1998 a 2009, dados a partir do VTI, PO e produtividade do trabalho e de acordo com a intensidade tecnológica comprovam a existência de heterogeneidade estrutural na indústria catarinense.
\end{abstract}

Palavras-chave: heterogeneidade estrutural, indústria de Santa Catarina, produtividade do trabalho.

\section{INTRODUÇÃ̃}

O tema heterogeneidade estrutural tem sido muito estudado atualmente, tendo sido considerado a causa para muitos dos problemas vividos pelos países que se encontram em estagio de subdesenvolvimento. A existência de

Mestranda em Economia pela Universidade Federal de Santa Catarina. E-mail: carolinascandido@gmail.com

Professor dos Cursos de Graduação e Pós-Graduação em Economia da Universidade Federal de Santa Catarina.

E-mail: fecario@yahoo.com.br

Doutorando em Economia pela Universidade Federal do Rio de Janeiro. E-mail: henrique.cavalieri@gmail.com 
uma estrutura marcada pela heterogeneidade produtiva de setores contribui fortemente para a reprodução da desigualdade social, concentração de renda, diferenciais no acesso à saúde e educação entre outras ocorrências, uma vez que a distinção do progresso técnico traz diferentes níveis de produtividade do trabalho, e por consequência em ganhos e acessos desiguais na sociedade.

Santa Catarina possui uma estrutura produtiva onde o setor industrial destaca-se por considerável contribuição ao longo do tempo. A construção do setor industrial foi privilegiada pela massa de imigrantes europeus que povoaram o Estado, trazendo a iniciativa empresarial e mão-de-obra qualificada, que somada à existência de recursos naturais possibilitou um caráter regionalizado e especializado do setor industrial, em conformação localizada de baixa concentração populacional. Auxiliando neste processo de desenvolvimento industrial encontram-se as ações do Estado, ao longo do tempo, impulsionando a dinâmica produtiva a partir de melhorias em condições infraestruturais, como os investimentos realizados em energia, transportes, educação - bem como em condições propícias para investimentos, concessão de crédito e de incentivos fiscais.

Ao fim e ao cabo, a estrutura industrial catarinense adentra os anos 2000 trazendo consigo questionamento sobre a existência de elevada heterogeneidade produtiva que se reproduz em termos de produtividade desigual entre atividades econômicas. Neste sentido, o presente artigo tem o objetivo de apresentar a produtividade do trabalho de Santa Catarina por intensidade tecnológica em termos de valor de transformação industrial e pessoal ocupado. Para tanto, está dividido em 5 seções, sendo que na $1^{\mathrm{a}}$. apresenta-se o propósito deste trabalho; na $2^{\text {a }}$. seção discute-se de forma sintética a relação entre heterogeneidade estrutural, produtividade do trabalho e progresso técnico; na $3^{\mathrm{a}}$. seção descreve-se o comportamento recente do crescimento da economia brasileira e catarinense; na $4^{\text {a }}$. seção faz avaliação dos indicadores que expressam a produtividade do trabalho na estrutura industrial de Santa Catarina; e por fim na $5^{\text {a }}$. seção apresentam-se os principais resultados.

\section{HETEROGENEIDADE ESTRUTURAL, PRODUTIVIDADE DO TRABALHO E PROGRESSO TÉCNICO}

No entendimento pensamento econômico estruturalista cepalino, o atraso em que se encontra a periferia latino-americana decorre, em muito, pela forma como se cria e difunde o progresso técnico. Nestes termos, para Rodriguez 
(1981, pg. 37), “[...] entende-se que centros e periferias se constituem historicamente como resultado da forma pela qual o progresso técnico se difunde na economia mundial". A maneira como penetra o progresso técnico - em estágio retardatário e de difusão desigual -, faz com seus frutos na periferia geram uma heterogeneidade na estrutura produtiva. Tal heterogeneidade possibilita a coexistem em seu seio, setores em que a produtividade alcança os níveis mais altos no padrão internacional, e atividades em que as técnicas de produção são arcaicas e a produtividade do trabalho é baixa.

Deve-se considerar que o desenvolvimento do progresso técnico, em nível mundial, mostra-se distinto na relação centro (países desenvolvidos) e periferia (países subdesenvolvidos). É considerado mais acelerado no centro do que na periferia, logo os incrementos da produtividade do trabalho, decorrentes da incorporação do progresso técnico ao processo produtivo, são menos intensos na segunda região do que na primeira. Esse diferencial entre progresso técnico e incremento produtivo do trabalho do centro em relação à periferia gera disparidade dos ritmos de aumento das respectivas produtividades médias, e assim da renda média geral (RODRIGUEZ, 1981).

Em correspondência com esta observação, Prebisch (2000b, pg. 83) aponta: “[...] enquanto os centros preservaram integralmente o fruto do progresso técnico de sua indústria, os países periféricos transferiram para eles uma parte do fruto do seu próprio progresso técnico". Segue afirmando (2000b, 72): "Daí a importância fundamental da industrialização dos novos países. Ela não constitui um fim em si, mas é o único meio de que estes dispõem para ir captando uma parte do fruto do progresso técnico, elevando progressivamente o padrão de vida das massas".

Por sua vez, para Prebisch, (2000a) o crescimento econômico da América Latina depende do aumento da renda per capita e do aumento da população. $\mathrm{O}$ aumento da renda per capita só ocorrerá mediante o aumento da produtividade ou, dada uma produtividade, através do aumento da renda por trabalhador na produção primária, comparada à renda dos países industrializados que importam parte dessa produção. Esse ajuste tende a corrigir a disparidade de renda provocada pela forma como o fruto do progresso técnico é distribuído entre centro e periferia. Logo, para aumentar a produtividade da população já existente, deve-se assimilar a técnica moderna, permitindo, assim, aumentar a produtividade do trabalho.

Sob condição do subdesenvolvimento periférico, a renda real por habitante cresce menos que a produtividade e a deterioração dos termos de 
intercambio implica em perda dos frutos do progresso técnico e/ou uma "transferência dos frutos do progresso técnico da periferia para o centro" (RODRIGUEZ, 1981, p. 21). Assim torna-se necessário expandir a atividade industrial na periferia, promover setores industriais, adotar técnicas modernas e incorporar mão de obra no processo de trabalho.

Bielschowsky (2000, pg. 32) aponta que a forma como o progresso técnico penetra na periferia gera heterogeneidade estrutural, trazendo por consequência: "[...] baixa produtividade média per capita reduzia a possibilidade de elevar as taxas de poupança nessas economias, limitando a acumulação de capital e o crescimento". Nestes termos, não é sem razão que o aumento da produtividade, que se atinge através do progresso técnico, deve vir acompanhado de um aumento do coeficiente de inversões; é nessa desigualdade que está à causa primeira da insuficiência dinâmica. $\mathrm{O}$ aumento da produtividade aumenta a renda e assim aumenta a capacidade de poupança, mas o capital requerido para absorver a mão de obra é superior à capacidade de poupança gerada no primeiro momento, sendo que apenas com o tempo esse equilíbrio é alcançado. Nesse caso, a restrição ao consumo e o suporte do capital internacional novamente se apresentam como fundamentais (PREBISCH, 2000b).

Tal preocupação retoma no final dos anos 1980 e mais intensamente na década de 1990, com o tema referente à "Transformação produtiva com equidade" com dois textos de Fernando Fajnzylber "A industrialização truncada da América Latina" de 1983 e "Industrialização na América Latina: da "caixa preta" ao "conjunto vazio", de 1990, com primeira versão datada de 1987. Nos textos citados é realizada uma análise do processo de industrialização latino-americano, identificando-se lacunas, falhas e distorções e é proposta uma nova industrialização baseada no conceito de eficiência que, por sua vez, estaria baseado na obtenção de "crescimento e criatividade" repousando na criação de um núcleo endógeno de progresso técnico como condições necessárias para penetrar e se manter no mercado internacional (BIELSCHOWSKY, 2000).

A heterogeneidade estrutural, confirmada como característica presente nas economias periféricas se apresenta através de brechas de produtividade que resulta em grande divergência de rendas. A redução das brechas produtivas, e assim redução da heterogeneidade, entre diferentes setores e agentes econômicos é buscada como forma de homogeneizar não só a produtividade, mas a renda da população e assim elevar a qualidade de vida (BIELSCHOWSKY, 2000). 
Fajnzylber introduziu a conceituação que serviria de referência à etapa organizada em torno da ideia de transformação produtiva com equidade. A novidade conceitual refere-se à reconsideração da estratégia de crescimento reconhecendo insuficiências no processo de industrialização passado, por ser esse pouco receptivo ao progresso técnico e sabotado por atitudes inadequadas das classes empresariais. A inclusão da América Latina no conjunto vazio, o conjunto do crescimento com equidade, se daria através da caixa preta do progresso técnico, estratégia que incluiria orientação à abertura comercial, até então não encontrada nas ideias passadas da Cepal. Com isso se evitaria o isolamento tecnológico e se aceleraria o processo de catching-up tecnológico com estratégia de crescimento com elevação do coeficiente de exportação (BIELSCHOWSKY, 2000).

Segundo Cepal (2008, pg. 23) "O crescimento sustentável depende da acumulação permanente de capacidades tecnológicas e de inovação, que consequentemente tende a diminuir a heterogeneidade estrutural..” A América Latina, levando isso conta, deve concentrar seus esforços para encontrar formas de aproveitar as janelas de oportunidades que têm dado lugar aos paradigmas tecnológicos surgidos. Em especial os paradigmas da informação e comunicação e da biotecnologia. Segue-se, ainda, a seguinte afirmação cepalina: "Os paradigmas tecnológicos reconfiguram a capacidade tecnológica e produtiva das empresas, sua competitividade externa e as relações entre os distintos setores da economia. São convergentes e capazes de afetar ou definir a trajetória de um conjunto muito amplo de setores".

\section{MOVIMENTOS RECENTES DAS ECONOMIAS NACIONAL E ESTADUAL}

Os anos 90 consolidam um novo modelo de desenvolvimento para a economia brasileira, rompendo-se com o desenvolvimentismo que havia caracterizado o crescimento econômico nacional, sobretudo nos anos de 1950 a 1980. De acordo com esse novo modelo, cujo viés é fortemente liberal, a promoção da concorrência externa deveria ser o novo motor do crescimento econômico, tendo em vista seu potencial de aumento da produtividade e incorporação e difusão de tecnologias modernas, além de induzir a alocação dos recursos na direção das vantagens comparativas nacionais, possibilitando a especialização local em segmentos específicos da cadeia de produção mundial. Nesse sentido, o eixo desse novo modelo pautou-se na 
abertura comercial e financeira, bem como em processos de privatização, ampliando, de um lado, a concorrência externa e eliminando, de outro, os monopólios estatais considerados ineficientes.

Nesse contexto, a abertura comercial resultou na entrada expressiva de produtos finais, partes, componentes e insumos internacionais via importações, pressionando os produtores e fornecedores nacionais a se adaptarem a essa maior concorrência. Além desse choque competitivo causado pela abertura comercial, a experiência de estabilização de preços com o Plano Real significou, de acordo com Ferraz, Kupfer e Iootty (2004), um segundo choque competitivo, tendo em vista que tal experiência pautou-se na forte apreciação cambial e na manutenção dos juros elevados, intensificando a exposição dos produtores nacionais às importações. Diante desse novo contexto de maior concorrência externa e menor participação do Estado na esfera produtiva, alguns resultados patentes do período foram o aumento do conteúdo importado da produção nacional - máquinas, equipamentos e insumos industriais -, a redução relativa do valor adicionado pela indústria nacional, a perda de elos produtivos do tecido industrial e a concentração relativa da produção em setores primários e de baixa intensidade tecnológica (COUTINHO, 1997; CARNEIRO, 2008).

No que diz respeito à economia catarinense, constata-se que o seu desenvolvimento insere-se na dinâmica e trajetória descritas pela economia nacional. Não obstante o fato de o tecido industrial catarinense se conformar a partir de diversas especificidades internas e com características setoriais próprias, como a especialização produtiva, a diversidade setorial, a organização produtiva localizada, tais fatores estão inseridos na lógica de desenvolvimento nacional, recebendo impulsos e impactos relacionados a esta vinculação. Nesse sentido, as especificidades da estrutura industrial catarinense entrelaçam e seguem a trajetória constituída pelo padrão de desenvolvimento industrial brasileiro (CAMPOS et all., 2002). Assim, nos anos 90, a indústria catarinense sofreu também os impactos da abertura comercial, tendo regredido em alguns casos, e em outros, conseguido se adaptar ao novo padrão concorrencial.

Os anos 2000, por sua vez, marcam um período de maior crescimento econômico em comparação à década de 90 , sobretudo a partir de 2003 , de forma que o crescimento do PIB nacional chegou a atingir 6,09\% em 2007, como se observa no Gráfico 1. Nessa década, houve uma expansão das exportações e dos saldos comerciais brasileiros, a despeito da trajetória de apreciação cambial que tem início no ano de 2003. Tal aumento das exporta- 
ções brasileiras é muitas vezes relacionado à expansão do comércio mundial, bem como ao aumento de preços das commodities agrícolas e minerais.

Porém, a despeito dessas constatações, nota-se que, no período de 2003 a 2010, a taxa de crescimento do produto industrial foi superior à taxa de crescimento do PIB nacional apenas em três anos: 2003, 2004 e 2010. Esse fato sinaliza, para autores como Oreiro e Feijó (2010), que o setor industrial não tem sido o setor que tem puxado o crescimento econômico do país, sugerindo que o país tem sofrido um processo de desindustrialização. Ademais, associando o dinamismo mais modesto da indústria nacional ao movimento de apreciação cambial, os mesmos autores sugerem que tal desindustrialização tem sido levada a cabo a partir do aumento das importações de produtos industriais e da forte concorrência de produtos chineses.

Ainda de acordo com esta demonstração gráfica, nota-se que a trajetória recente de maior dinamismo econômico do país foi severamente abortada pela crise internacional que atingiu o país de forma mais intensa a partir do segundo semestre de 2008. O setor industrial em particular, sendo um setor fortemente elástico em relação ao desempenho da economia nacional, foi gravemente prejudicado, recuando 8,73\% em 2009. Em 2010, o país demonstra sinais de recuperação, com o PIB expandindo-se 7,53\% e a indústria 10,14\%, o que, apesar de ser um fato positivo, não deve ser superestimado, tendo em vista que tal crescimento é expresso em relação ao ano de 2009, ou seja, a um ano de decrescimento.

Gráfico 1 - Brasil - Taxa de variação real do PIB (\%), do valor adicionado da Indústria de Transformação (\%) e taxa de câmbio (RS\$/US\$), 2003-2010.

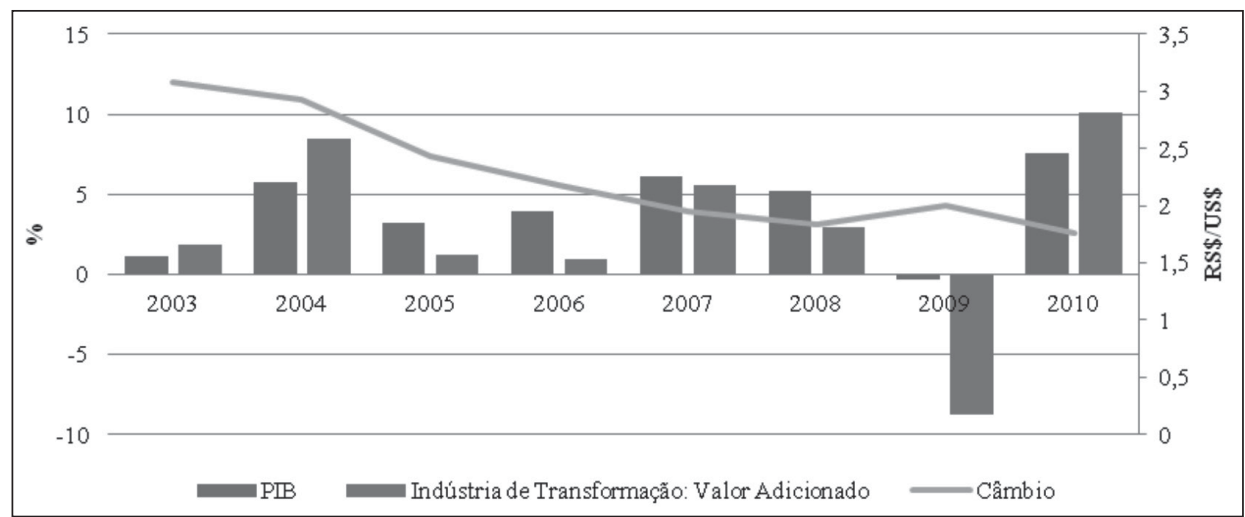

Fonte: SCN/IBGE. 
Gráfico 2 - Santa Catarina - Taxa de variação real do PIB (\%), do valor adicionado da Indústria de Transformação (\%) e taxa de câmbio (RS\$/ US\$), 2003-2008.

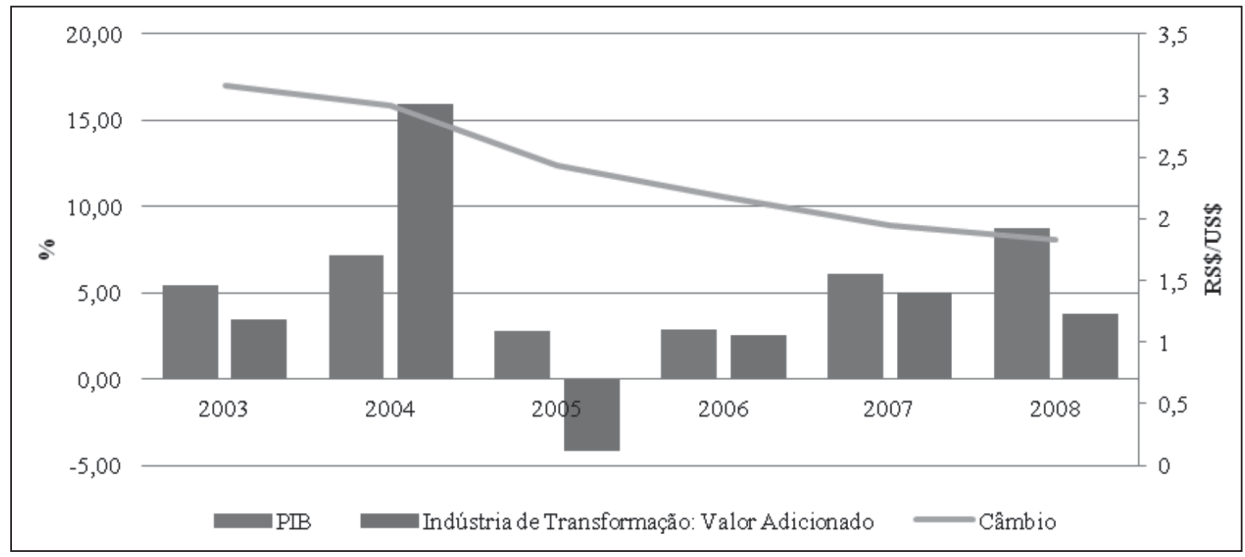

Fonte: SCN/IBGE.

No que diz respeito à economia catarinense, cuja análise estende-se apenas até 2008 devido à disponibilidade de dados, constata-se certa semelhança com a trajetória da economia nacional, como se verifica no Gráfico 2. O PIB do Estado ingressou em uma trajetória de crescimento a partir de 2005 , chegando a atingir a expressiva taxa de $8,77 \%$ em 2008. Porém, o setor industrial catarinense parece não ter sido o fator dinâmico primordial desse movimento, tendo em vista que sua taxa de crescimento foi superior ao crescimento do PIB estadual apenas em 2004, com um forte aumento de $15,95 \%$, recuando em 2005 em 4,13\%. Esse fato sinaliza a possibilidade de ocorrência de desindustrialização também em nível estadual, tendo em vista a dificuldade da indústria catarinense, progressivamente adicionar mais valor à sua produção.

De fato, o movimento de apreciação cambial que se observa após 2003, associado à devastadora concorrência chinesa, tem atingido severamente diversos segmentos industriais, principalmente os tradicionais, os quais tem grande peso na estrutura industrial de Santa Catarina. Assim, segmentos como, por exemplo, têxtil, calçadista, cerâmico e moveleiro, têm sofrido severos impactos, reduzindo seus saldos comerciais e expandindo o conteúdo importado da produção local. 


\section{AVALIAÇÃO DA PRODUTIVIDADE DO TRABALHO DA IN- DÚSTRIACATARINENSE POR INTENSIDADE TECNOLÓGICA}

A produtividade da indústria catarinense é apresentada em função do Valor de Transformação Industrial (VTI) por Pessoal Ocupado (PO), segundo a classificação de intensidade tecnológica da Organização para a Cooperação e Desenvolvimento Econômico (OCDE). Para fazer a análise da produtividade do trabalho da indústria catarinense de acordo com a classificação por intensidade tecnológica, foi necessário o agrupamento dos segmentos da Pesquisa Industrial Anual (PIA) - Classificação Nacional de Atividades Econômica (CNAE) 1.0 de acordo com a metodologia proposta a partir da tabela de correspondência apresentada por OCDE (2011). A partir de 2008 a PIA passou a ser classificada nos termos do novo código - CNAE 2.0. Tal mudança tornou necessária a conversão do CNAE 2.0 para o CNAE 1.0, para então seguir com o agrupamento de acordo com a metodologia proposta pela OCDE.

Os dados do VTI e PO são coletados desde 1996 e divulgados a partir da PIA do Instituto Brasileiro de Geografia e Estatística (IBGE). A evolução de tais variáveis para o estado de Santa Catarina é apresentada, a seguir, focando a análise em triênios a partir de 1998. Para o último triênio, convém ressaltar a adoção do novo código CNAE, limitando a comparação de dados com os triênios anteriores.

\subsection{Valor de Transformação Industrial (VTI) de Santa Catarina}

O valor de transformação industrial (VTI) capta a diferença entre o valor bruto da produção indústria - valor das receitas com vendas das empresas de um determinado setor - e os custos das operações industriais. Segundo IBGE (2011) O VTI é diferença entre o valor bruto da produção industrial e o custo com as operações industriais. Indica o quanto foi incorporado de valor no produto fabricado (CARIO, 2008). A evolução do VTI do estado de Santa Catarina por intensidade tecnológica encontra-se no Gráfico 3. 
Gráfico 3 - VTI por Intensidade Tecnológica - Santa Catarina, 1998-2009

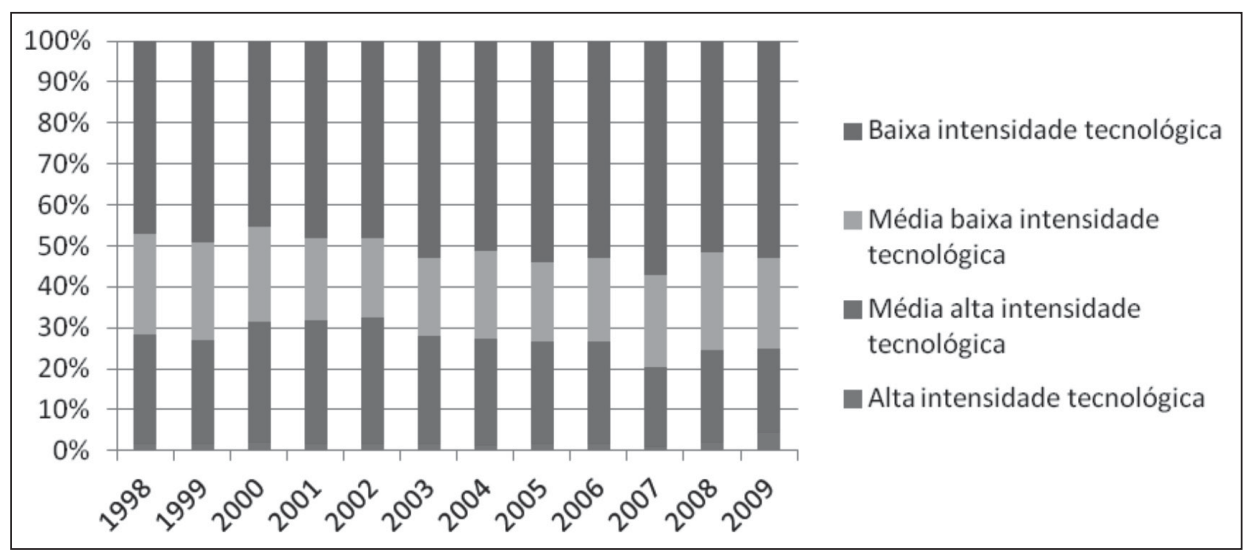

Fonte: Elaboração própria baseada em IBGE - Pesquisa Industrial Anual Empresa

Em termos de participação, observa-se que o segmento que detêm maior representatividade na indústria catarinense é o segmento de baixa intensidade tecnológica. Tal segmento chega a representar até $57,09 \%$ da total do VTI de Santa Catarina no ano de 2007. Até tal ano, o segmento de baixa intensidade tecnológica seguiu uma tendência ascendente de participação no VTI total. O Gráfico 4 apresenta as categorias da indústria existentes dentro do segmento de baixa intensidade tecnológica.

Gráfico 4 - VTI do segmento de Baixa Intensidade Tecnológica - Santa Catarina

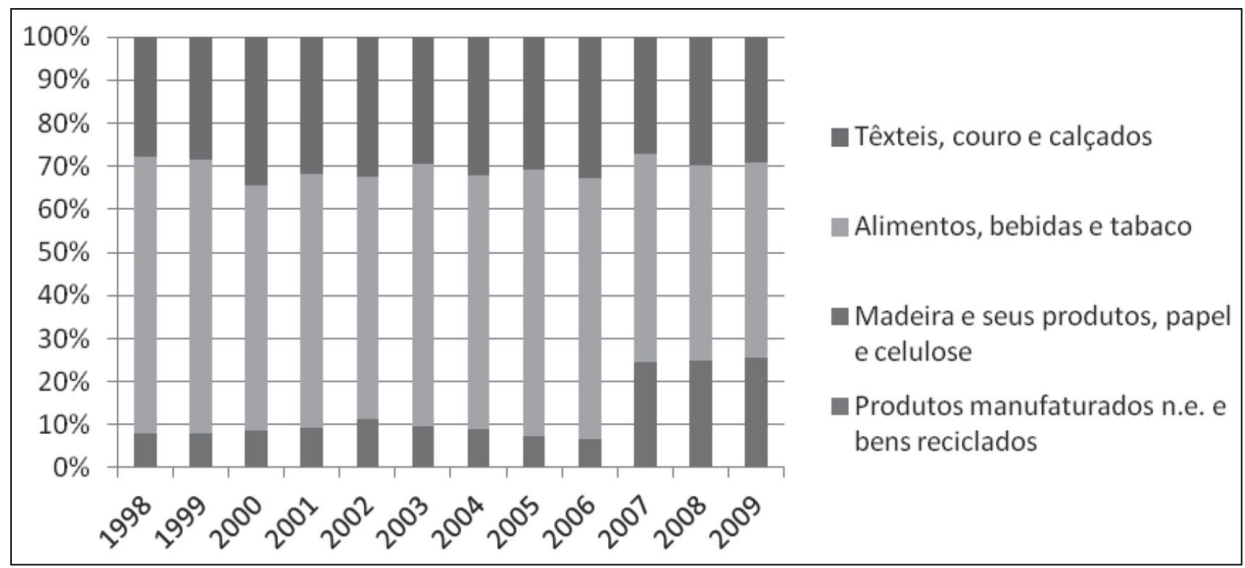

Fonte: Elaboração própria baseada em IBGE - Pesquisa Industrial Anual Empresa 
Constata-se, dentro do segmento de baixa intensidade tecnológica, a categoria alimentos, bebidas e tabaco apresentando grande participação no conjunto do valor agregado por este segmento, com um máximo de $64,17 \%$ do VTI total em 1998. Tal representatividade expressa que de cada três unidades de valor acrescida, duas provinham desta categoria produtiva industrial. Durante os três últimos anos da série analisada tal participação foi reduzida para 48,40\%, 45,37\% e 45,24\%, em 2007, 2008 e 2009, respectivamente. A participação do VTI da categoria têxteis, couro e calçados também é representativa com uma participação máxima de $32,76 \%$ em 2006, figurando como segundo maior grupo de segmento produtivo mais representativo, dentro do segmento de baixa intensidade tecnológica da indústria catarinense.

Para o segmento de média baixa intensidade tecnológica a participação encontra-se bastante próxima do segmento de média alta intensidade tecnológica. O primeiro apresenta uma participação máxima de $24,75 \%$ do VTI total no ano primeiro analisado, enquanto para o mesmo ano, o segmento de média alta intensidade tecnológica expressa $26,58 \%$ de participação em relação ao VTI total. Todavia, verifica-se evolução na representatividade dado que no ano de 2002 que tal segmento apresenta maior participação em relação ao VTI total, 30,79\%. O Gráfico 5 expressa o VTI do segmento de média baixa intensidade tecnológica em suas categorias produtivas.

Gráfico 5 - VTI do segmento de Média Baixa Intensidade Tecnológica Santa Catarina

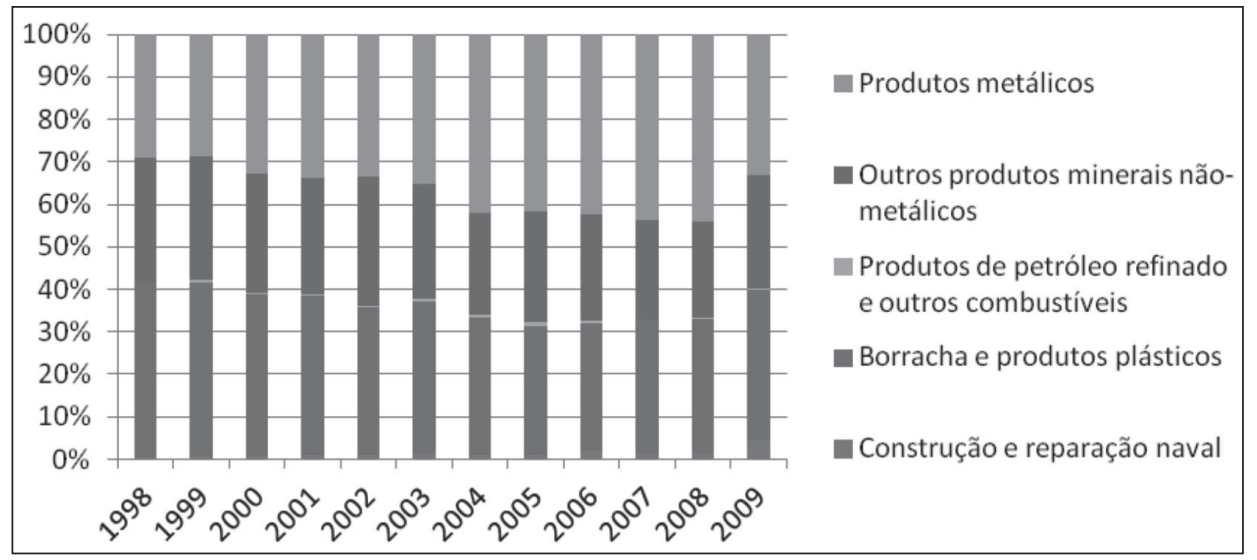

Fonte: Elaboração própria baseada em IBGE - Pesquisa Industrial Anual Empresa 
No segmento de média baixa intensidade tecnológica, as categorias borracha e produtos plásticos, produtos metálicos e outros produtos minerais não-metálicos são as mais significativas no conjunto do segmento analisado. A categoria borracha e produtos plásticos apresenta um máximo de $41,01 \%$ do VTI total do segmento, porém a tendência é decrescente até o ano de 2007. É interessante observar que tal tendência também ocorre nas categorias produtos metálicos e outros produtos minerais não-metálicos.

No tocante ao segmento de média alta intensidade tecnológica, observa-se no Gráfico 6, as categorias máquinas e equipamentos mecânicos e máquinas e equipamento elétricos são as que se apresentam mais significativas. É interessante observar que em ambas, a mudança do código CNAE faz bastante diferença. A categoria máquinas e equipamentos elétricos que apresenta um máximo de participação do VTI do segmento de $29,22 \%$ em 2005 , se eleva para $51,77 \%$ em 2007 , seguida para o patamar de $61,71 \%$ em 2009. Tal comportamento é visível na categoria máquinas e equipamentos mecânicos, onde o salto é inverso, passa de 44,34\% em 2006 para $25,34 \%$ em 2007.

Gráfico 6 - VTI do segmento de Média Alta Intensidade Tecnológica - Santa Catarina

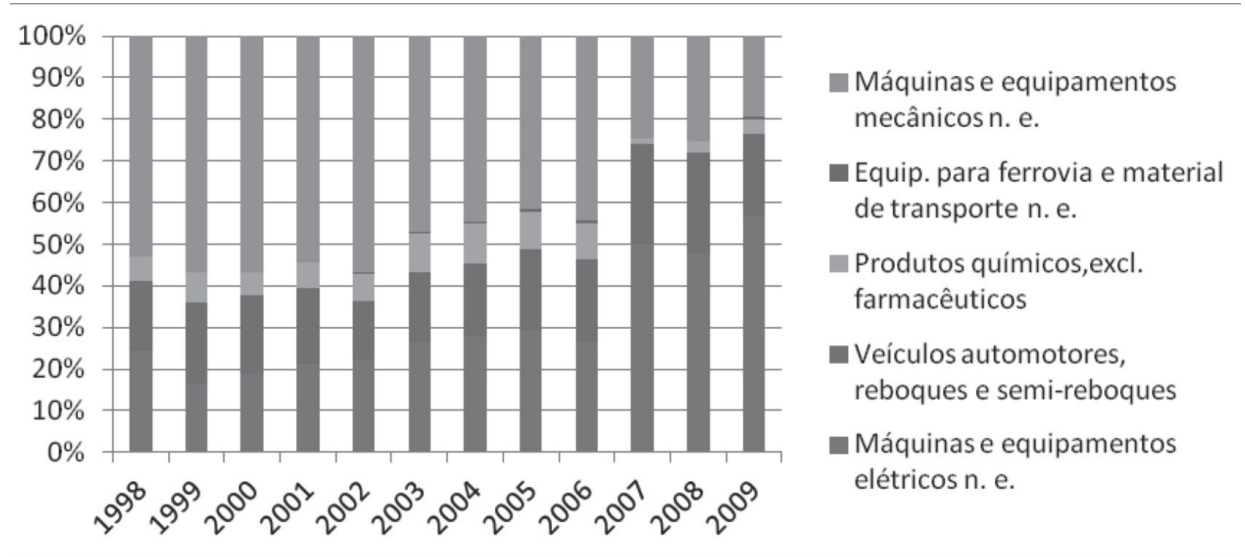

Fonte: Elaboração própria baseada em IBGE - Pesquisa Industrial Anual Empresa 
A participação do VTI do segmento de alta intensidade tecnológica em relação ao total por categoria industrial participante, expressa no Gráfico 7, aponta a indústria farmacêutica como mais expressiva na maioria dos anos considerados. Porém, demonstra tendência decrescente durante a maior parte da serie analisada, de percentual próximo a 70\% do VTI em 1998 alcança 40\% em 2006, e depois com a mudança de metodologia do CNAE, reduz, ainda mais, a representatividade e alcança representatividade ao redor de $20 \%$, em 2009.

As categorias instrumentos médicos de ótica e precisão e equipamentos de rádio, TV e comunicação também apresentam significância relevante na série, obtendo um máximo de $29,86 \%$ em 2002 na primeira, e $27,05 \%$ em 2004 na segunda categoria industrial, considerando o período anterior a 2007. Registra-se maior presença representativa da categoria material de escritório e informática no último triênio, 2007-2009, em demonstração da importância desta categoria na constituição do valor agregado entre as indústrias de alta intensidade tecnológica, não tão presente em período anterior.

Gráfico 7 - VTI do segmento de Alta Intensidade Tecnológica - Santa Catarina

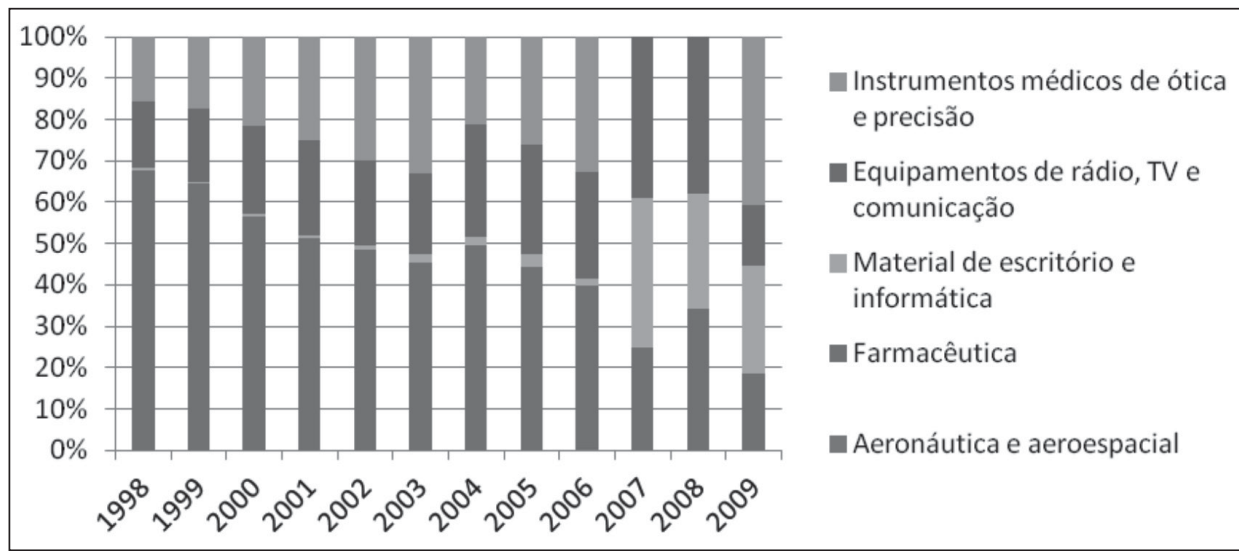

Fonte: Elaboração própria baseada em IBGE - Pesquisa Industrial Anual Empresa 
Considerando a estrutura industrial de Santa Catarina, em quadro amplo composto por todos os segmentos por intensidade tecnológica e suas categorias mais representativas, observa-se na Tabela 1 que o segmento mais representativo, durante todo o período estudado é o de baixa intensidade tecnológica. Isso significa que o grupo de indústrias que mais agrega valor ao produto fabricado em Santa Catarina não são os de média e de alta tecnologia. Considerando, apenas o último triênio, 2007-2009, registra-se que do valor gerado a mais pela estrutura industrial, 53,93\% foram de responsabilidade das indústrias de madeira e seus produtos e papel e celulose; alimentos, bebidas e tabacos; e têxteis, couro e calçados.

Em lado oposto, encontram-se os de média alta e alta tecnologia, cujos percentuais representativos figuram em $20,76 \%$ e $2,43 \%$, respectivamente. Estes últimos setores são produtores e difusores do progresso técnico, portanto categorias industriais que impulsionam o desenvolvimento na economia em proporções significativas aos produtores de baixa tecnologia. A dinâmica imposta pelos segmentos de média alta e alta tecnologia irradia outros segmentos produtivos, impulsionando tanto à frente como para trás os processos produtivos dos segmentos que participam das demais cadeias produtivas.

No conjunto da estrutura industrial de Santa Catarina, registra-se que $76,81 \%$ do VTI provêm dos grupos de média baixa, 22,88\%, e baixa intensidade tecnológica, 53,93\%, no último triênio em análise, 20072009. Esta representatividade expressa que praticamente $2 / 3$ do valor gerado provêm de indústria de reduzido conteúdo tecnológico. Aponta para a conclusão de que a dominância na incorporação de valor no processo produtivo estadual está fundada em bens de consumo final e bens intermediários, cujas funções são de baixa capacidade de impulsionar a dinâmica produtiva, ainda que importantes na reprodução da força de trabalho, para o primeiro agrupamento, e de composição na fabricação de outros produtos, no segundo grupo de indústrias. 


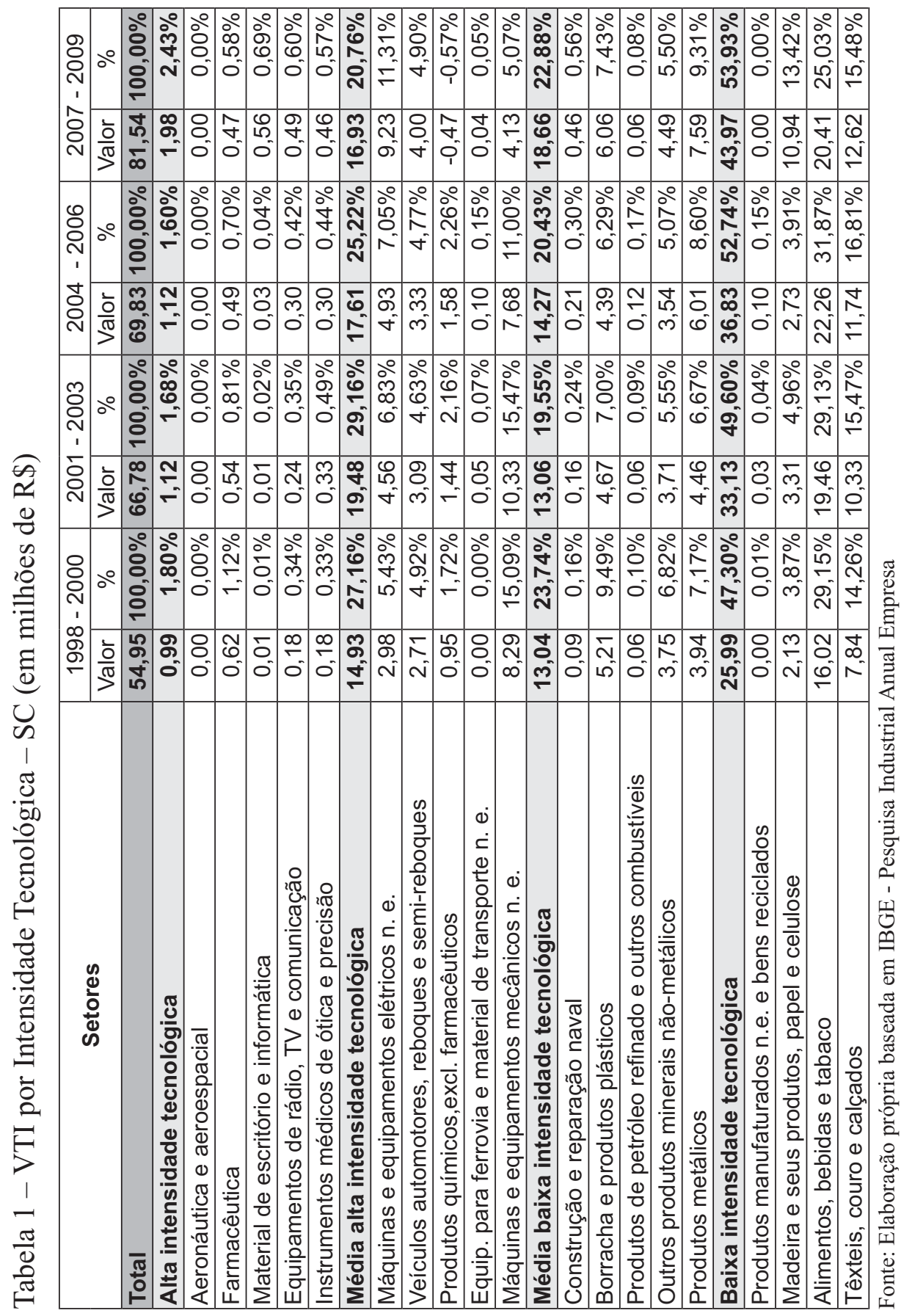




\subsection{Pessoal Ocupado (PO) de Santa Catarina}

O IBGE (2011) considera o pessoal ocupado (PO) a totalidade das pessoas ocupadas em 31 de dezembro do ano de referência independente do vínculo empregatício, remuneradas diretamente pela empresa. A partir desta definição, apresenta-se n Gráfico 8, evolução do PO do estado de Santa Catarina, dividido por intensidade tecnológica para o período de 1998 a 2009. Observa-se que o segmento de baixa intensidade tecnológica apresenta maior participação no PO total, alcançado um máximo de $61,60 \%$ de participação no ano de 1999 . Durante toda a série analisada a participação de tal segmento se manteve bastante estável, com poucas variações e sem tendência definida.

Gráfico 8 - PO por Intensidade Tecnológica - Santa Catarina

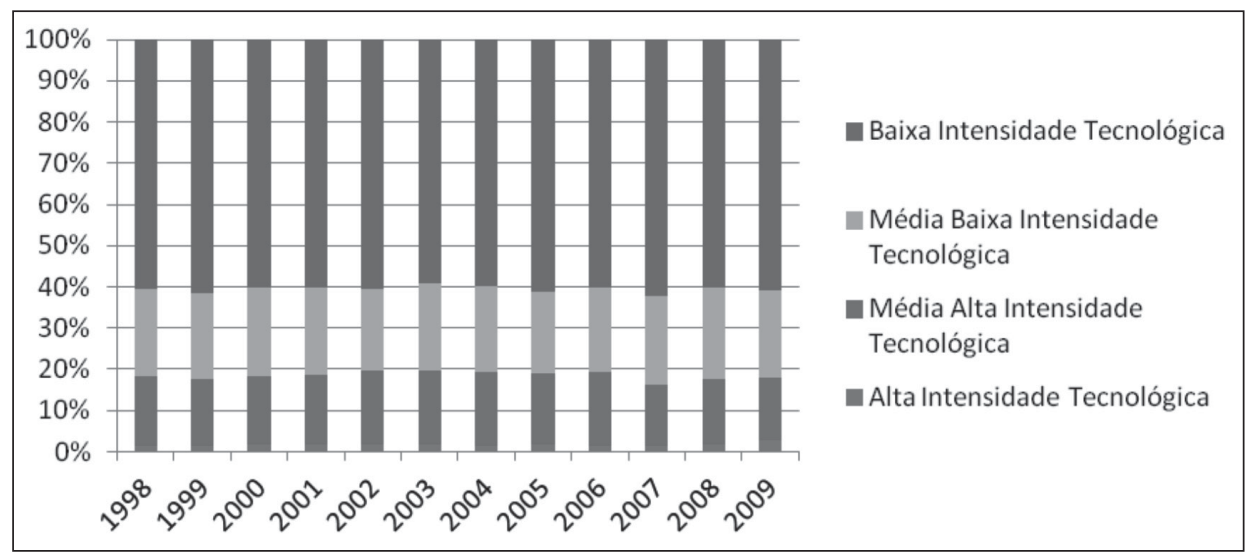

Fonte: Elaboração própria baseada em IBGE - Pesquisa Industrial Anual Empresa

A maior participação do segmento de baixa intensidade tecnológica fica por conta das categorias alimentos, bebidas e tabaco e têxteis, couro e calçados. A primeira apresenta uma série bem estável ao longo dos anos estudados enquanto a segunda se caracteriza por uma queda considerável a partir de 2007, podendo ser inclusive atribuída à mudança do código CNAE devido à volta da estabilidade em 2007, 2008 e 2009. Tais categorias industriais chegam a representar em torno de $80 \%$ do pessoal ocupados nos 
segmentos de baixa intensidade tecnológica, justificado, em grande monta, por congregarem atividades intensivas em mão-de-obra.

Gráfico 9 - PO do segmento de Baixa Intensidade Tecnológica - Santa Catarina

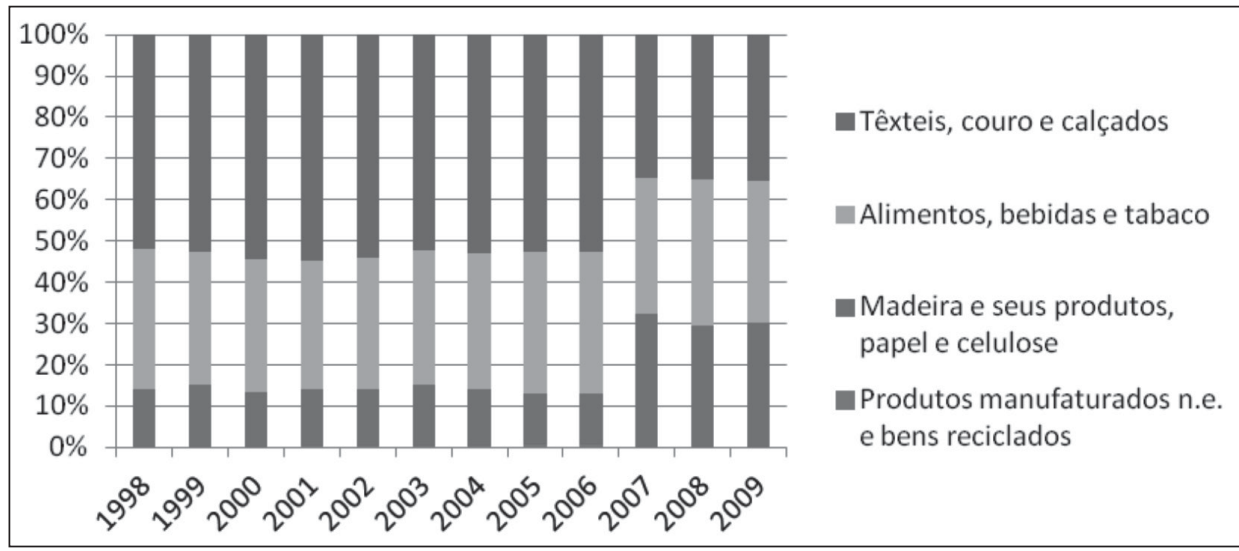

Fonte: Elaboração própria baseada em IBGE - Pesquisa Industrial Anual Empresa

O segundo segmento industrial mais representativo em pessoal ocupado é o de média baixa intensidade tecnológica, chegando a obter a máxima participação de 22,20\% em 2008. A trajetória dos anos estudados permite observar a não ocorrência de tendência à redução ou de aumento desta proporção. Neste segmento de intensidade tecnológica destaque para as categorias produtos metálicos, outros produtos minerais não-metálicos e borracha e produtos plásticos são as mais representativas. A primeira apresenta uma média de $30,25 \%$ de participação apresentando tendência crescente, a segunda com média de $30,51 \%$ de participação, porém apresentando tendência decrescente e a última com tendência estável de 35, 14\% de participação em relação ao PO total do segmento. 
Gráfico 10 - PO do segmento de Média Baixa Intensidade Tecnológica Santa Catarina

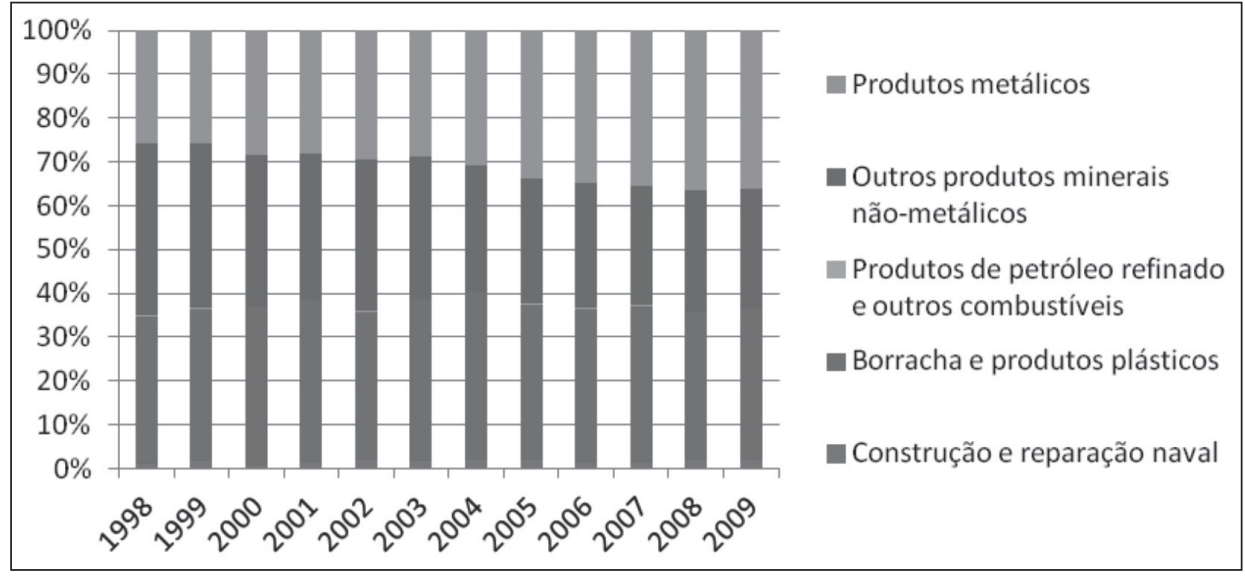

Fonte: Elaboração própria baseada em IBGE - Pesquisa Industrial Anual Empresa

As outras categorias industriais - fabricação de petróleo refinado e outros combustíveis e construção e reparação naval - são inexpressivas em relação às outras categorias citadas, expressando, na verdade, a baixa inserção na estrutura produtiva industrial de Santa Catarina. Não há no Estado uma bacia petrolífera, nem tampouco se explora, em grande intensidade, a indústria de construção e reparação naval, apesar de contar com parte litorânea de seu território.

Os segmentos de média alta e alta intensidades tecnológicas chegam a representar, o primeiro, um máximo de $17,85 \%$ de participação no PO total em 2006, e um máximo de 2,74\% de participação em 2009, com destaque de que este se trata de um ano atípico, contando que nos outros anos a participação beira os 1,70\%. Tais segmentos são poupadores de mão-de-obra e constituem intensivo em capital, ainda que estas características estejam mais presente no segundo do que no primeiro grupo de indústrias citadas. 
Gráfico 11 - PO do segmento de Média Alta Intensidade Tecnológica Santa Catarina

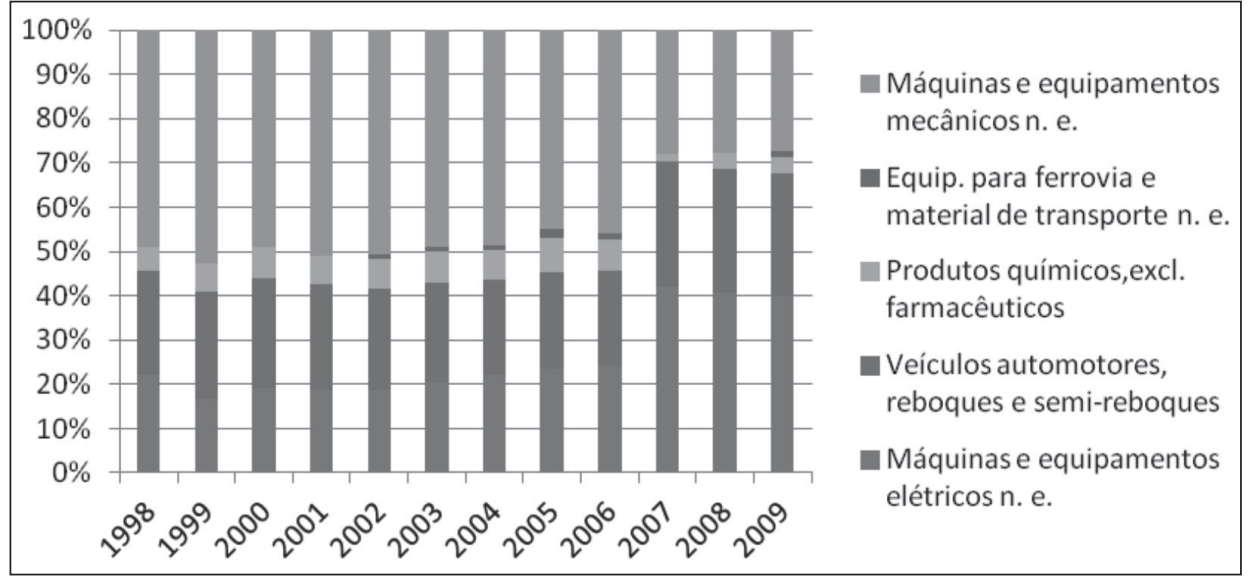

Fonte: Elaboração própria baseada em IBGE - Pesquisa Industrial Anual Empresa

No segmento de média alta intensidade tecnológica a categoria de maior participação é a de máquinas e equipamentos mecânicos, com quase 50\% da participação de pessoal ocupado no total, contudo tal categoria apresenta queda de participação no total ao longo do período em estudo, conforme expressa o Gráfico 12. A categoria máquinas e equipamentos elétricos apresenta tendência forte de aumento de participação durante todo o período, enquanto, a categoria veículos automotores, reboques e semi-reboques se manteve relativamente estável. As demais categorias industriais presentes neste grupo por intensidade tecnológica mostram-se pouco representativas. 
Gráfico 12 - PO do segmento de Alta Intensidade Tecnológica - Santa Catarina

\begin{tabular}{|c|c|}
\hline \\
\hline \multicolumn{2}{|r|}{ Instrumentos médicos de ótica } \\
\hline $80 \%$ & e precisão \\
\hline $70 \%$ & Equipamentos de rádio, TV e \\
\hline $60 \%$ & comunicação \\
\hline $50 \%$ & \\
\hline $40 \%$ & $\begin{array}{l}\text { Material de escritorio e } \\
\text { informática }\end{array}$ \\
\hline $30 \%$ & \\
\hline $20 \%$ & Farmacêutica \\
\hline $10 \%$ & \\
\hline $0 \%$ & - Aeronáutica e aeroespacial \\
\hline
\end{tabular}

Fonte: Elaboração própria baseada em IBGE - Pesquisa Industrial Anual Empresa

No segmento de alta intensidade tecnológica, as categorias farmacêutica, instrumentos médicos de ótica e precisão e equipamentos de rádio, TV e comunicação são as registram maior representatividade no PO total do segmento. A primeira apresenta um máximo de participação de 43,02\% em 1998, e desde então, registra queda persistente em sua participação. A categoria instrumentos médicos de ótica e precisão apresenta um máximo de participação de 35,10\% em 2009 no PO total do segmento, a série é estável. A maior participação alcançada pela categoria equipamento de rádio, TV e comunicação é alcançada em 2004 com 35,24\% da participação total do PO do segmento. A trajetória dos anos mostra a ocorrência de tendência de recuperação da participação desta categoria industrial até 2004, quando se inicia percurso de queda da representatividade na estrutura industrial do Estado no tocante ao PO.

A Tabela 2 apresenta o PO do estado de Santa Catarina dividida por segmentos de intensidade tecnológica e agrupado em triênios e sinaliza para a concentração em segmentos de conteúdo tecnológico reduzido. Os triênios mostram que a participação da PO das indústrias de baixa tecnologia gira em torno de $60 \%$ do total. Somada com a representatividade das indústrias de média baixa intensidade tecnológica, cuja participação situa-se em torno dos $20 \%$, alcança-se um total de $80 \%$ do PO em atividades industriais de reduzido conteúdo tecnológico. 
Heteorogeneidade estrutural da indústria do estado de Santa Catarina: algumas evidências empíricas

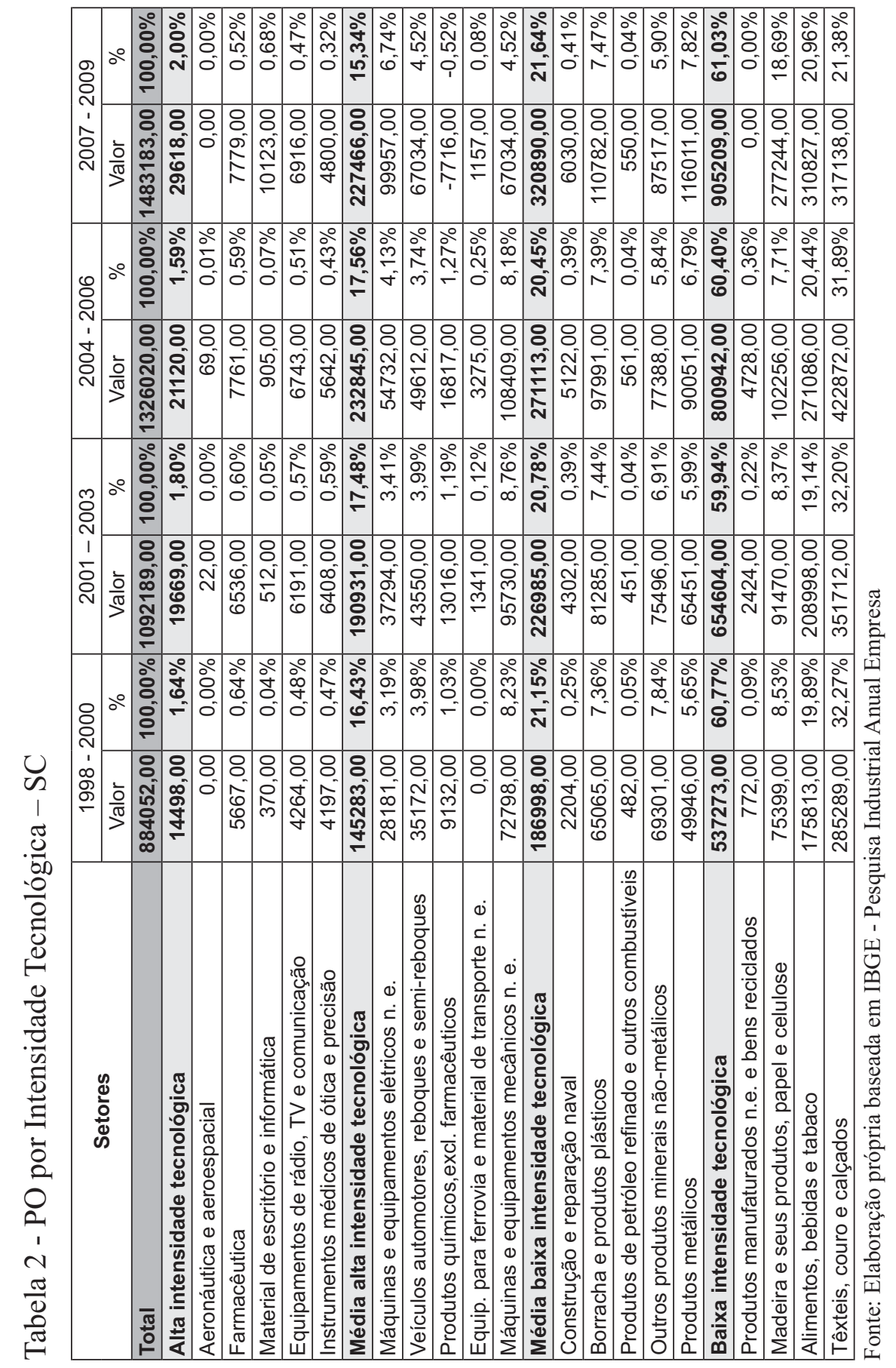

Textos de Economia, Florianópolis, v. 15, n. I, p.89-121, jan./jun.2012 


\subsection{Produtividade do trabalho (VTI/PO) de Santa Catarina}

A produtividade de trabalho no presente artigo é calculada como a proporção do VTI por pessoal ocupado. Ela indica o quanto cada posto de trabalho está gerando em termos valor agregado no segmento industrial. Segundo o referencial teórico cepalino, adotado no presente trabalho, um aumento da produtividade ao permitir que se gerem mais riqueza com o mesmo recurso de mão-de-obra, encadeia um aumento da renda per capita, refletindo, por conseguinte, nas condições de vida da sociedade.

Segundo Furtado (1961), o aumento da produtividade do trabalho é auferido ao se aumentar a relação capital/trabalho. Tal relação tem desdobramento no âmbito do desenvolvimento econômico. Pois, este último se alcança através da introdução de fatores de produção que façam com que a produtividade do trabalho aumente e esta ao se elevar permite que a sociedade se beneficie pela aquisição através de preços menores e qualidades maiores. Nestes termos, o aumento da produtividade se alcança através da incorporação do progresso técnico ao trabalho reservando, desta forma, papel determinante do progresso técnico no desenvolvimento econômico dos países.

A indústria, por ser um setor intensivo em capital, destaca-se por ser naturalmente aumentadora da produtividade do trabalho através da inserção de técnicas produtivas que vem se aperfeiçoando num processo contínuo de progresso tecnológico. Tal constatação torna a indústria um setor importante para a intensificação do desenvolvimento econômico. 
Gráfico 13 - Produtividade do Trabalho (VTI/PO) por Intensidade Tecnológica - Santa Catarina

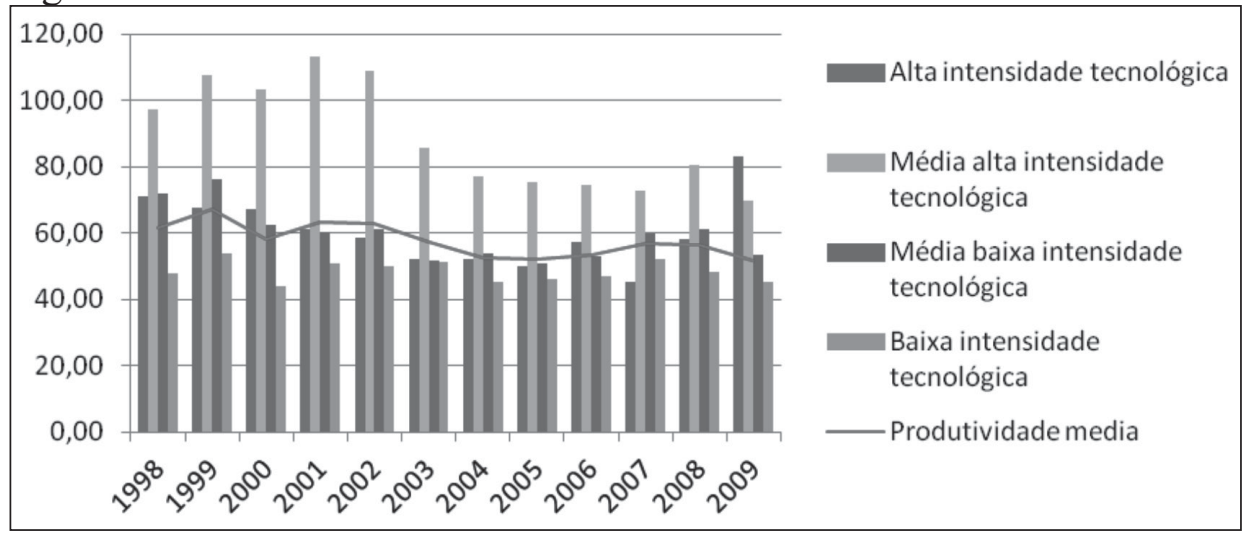

Fonte: Elaboração própria baseada em IBGE - Pesquisa Industrial Anual Empresa

Considerando tais aspectos, apresenta-se a evolução da produtividade do trabalho por intensidade tecnológica de Santa Catarina no Gráfico 13. Como se pode observar apenas o setor de média alta intensidade tecnológica apresenta produtividade superior à produtividade média durante toda a série. O setor de alta intensidade tecnológica, também considerado portador de progresso técnico, não apresenta nível superior à média ao longo dos anos, com presença relevante apenas no último ano considerado. Tal ocorrência demonstra baixa inserção na estrutura industrial catarinense, que se traduz em reduzida incorporação de valor agregado por trabalhador.

Comparando a produtividade dos diversos segmentos em relação ao segmento mais produtivo, o segmento de média alta intensidade tecnológica, observa-se, que os segmentos que mais se aproximam da produtividade do setor de média alta intensidade tecnológica são os segmentos de alta intensidade tecnológica e média baixa intensidade tecnológica, conforme demonstra o Gráfico 14. Porém, com exceção do último ano em análise, 2009 , todos os demais o desempenho fica abaixo da média alta intensidade tecnológica, demonstrando que os demais segmentos não acompanham o nível de agregação de valor por trabalhador do segmento referência. 
Gráfico 14 - Produtividade do Trabalho (VTI/PO) relativa por Intensidade Tecnológica - Santa Catarina

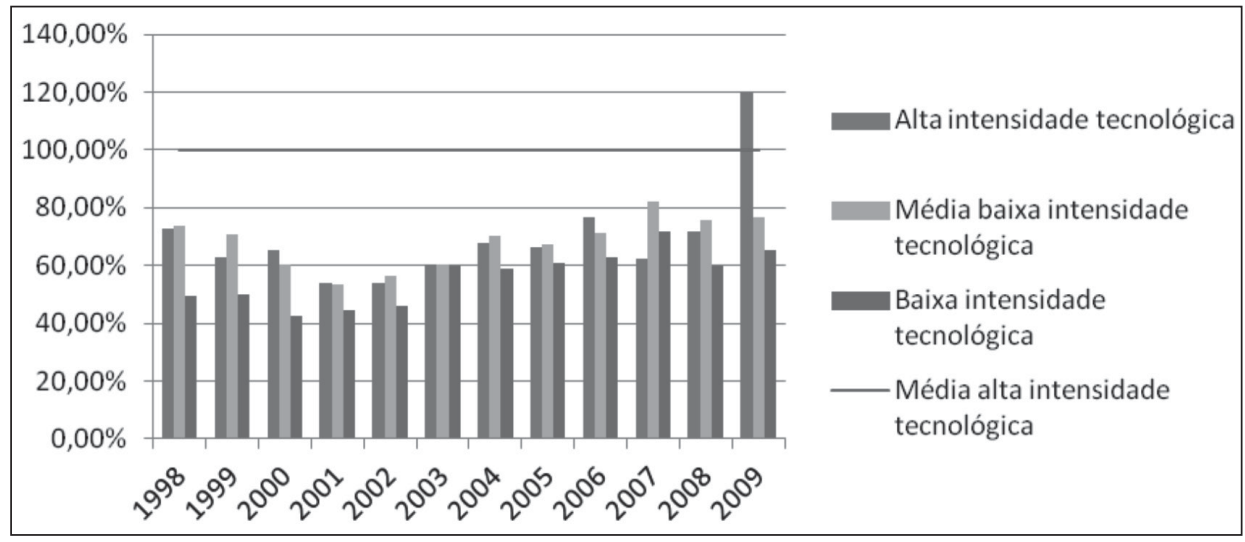

Fonte: Elaboração própria baseada em IBGE - Pesquisa Industrial Anual Empresa

No tocante ao segmento de baixa intensidade tecnológica registra-se movimento de elevação da produtividade do trabalho, e depois redução a partir de 2008 da produtividade de tal segmento. A produtividade do mesmo alcançou um máximo de $71,76 \%$ da produtividade do setor de média alta intensidade tecnológica em 2007. Este fato demonstra que apesar deste segmento ser tradicionalmente portador de baixa agregação de valor, registram-se esforços, ao longo de um período, voltado a agregar mais valor por trabalhador.

Ao tratar de diferencial produtivo entre segmentos, comparando a representatividade com a média da produtividade do segmento mais produtivo - de média alta intensidade tecnológica -, observa-se que o segmento de alta intensidade tecnológica alcança o percentual médio de $65,57 \%$, o de média baixa intensidade tecnológica, $70,40 \%$ e para o setor de baixa intensidade tecnológica, 59,10\%. Tais números indicam que Santa Catarina apresenta, sim, considerável heterogeneidade produtiva, pois tem segmentos que beiram os $60 \%$ da produtividade do setor mais produtivo. 
Gráfico 15 - Evolução da Produtividade do Trabalho (VTI/PO) por Intensidade Tecnológica - Santa Catarina

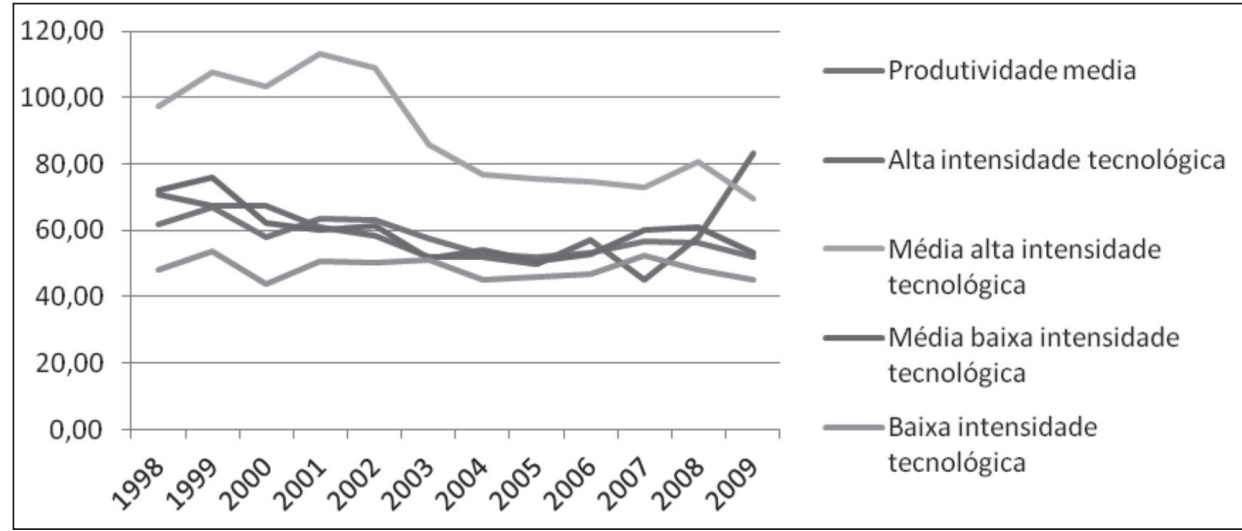

Fonte: Elaboração própria baseada em IBGE - Pesquisa Industrial Anual Empresa

Quando a heterogeneidade produtiva se reproduz ao longo do tempo é possível considerá-la como uma característica da estrutura produtiva estudada, desta forma, ao analisar a evolução no tempo da heterogeneidade produtiva se evidencia a existência ou não de uma heterogeneidade estrutural. No Gráfico 15 observa-se que a tendência das séries de todos os segmentos estudados aponta para a não convergência produtiva da estrutura produtiva de Santa Catarina. A heterogeneidade produtiva constitui uma característica da estrutura produtiva catarinense, expressando a existência de setores distintos nos termos de valor gerado e de produtividade alcançada. A convivência de padrões tecnológicos diferentes constitui marca da heterogeneidade estrutural da indústria em Santa Catarina. 


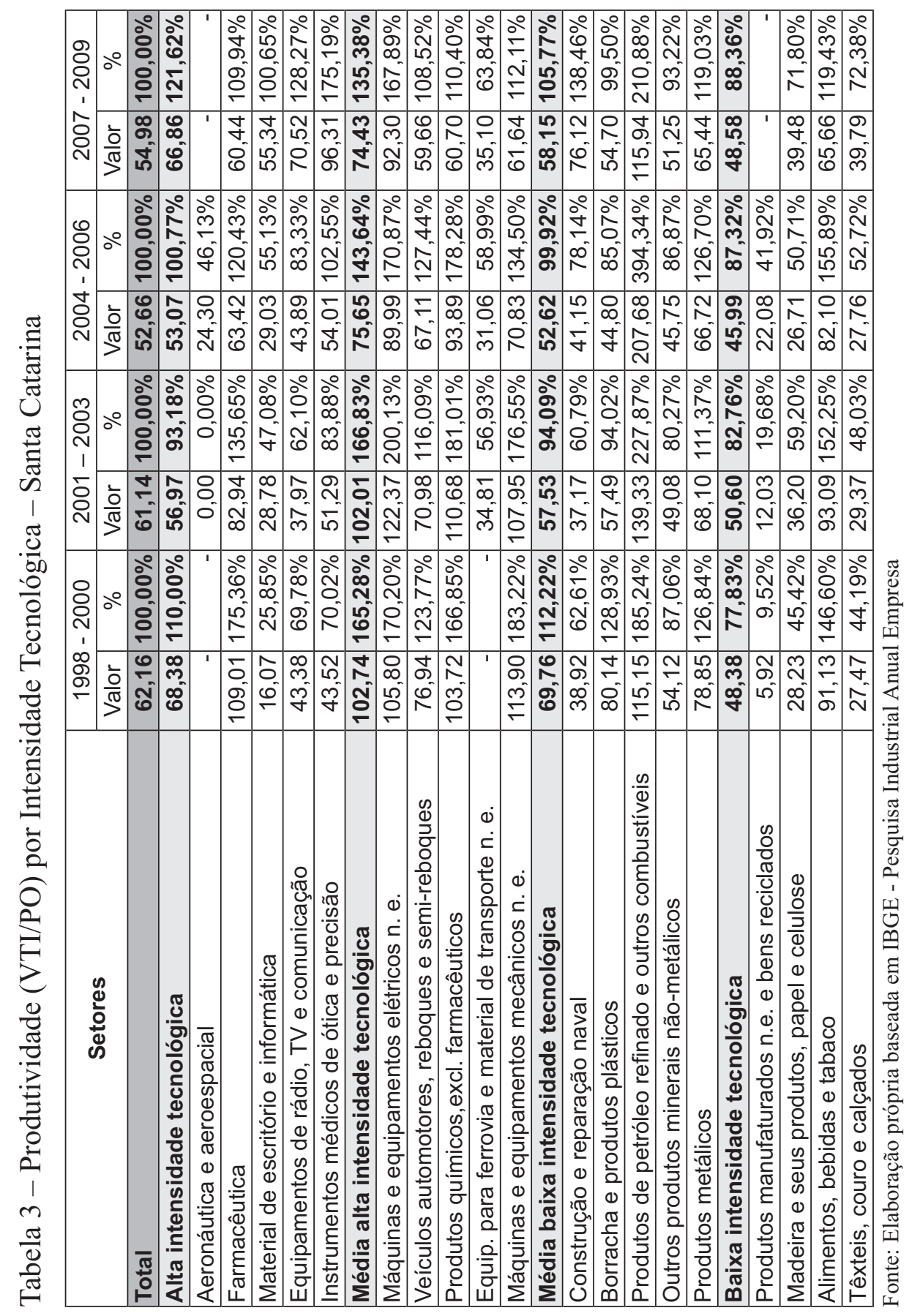


A produtividade do trabalho segundo os segmentos e suas categorias permite conhecer nos segmentos industriais por intensidade tecnológica, as categorias que mais se destacam. Segundo a Tabela 3, no segmento de alta intensidade tecnológico a indústria farmacêutica é a que eleva a produtividade do segmento. Referente ao segmento de média alta intensidade tecnológica todas as categorias apresentam produtividade elevada, que justifica a alta produtividade do segmento. No segmento de média baixa intensidade tecnológica o segmento que puxa a produtividade é o segmento de produtos de petróleo refinado e outros combustíveis. Por sua vez, a categoria de alimentos, bebidas e tabaco é a que eleva a produtividade do segmento de baixa intensidade tecnológica.

\subsection{Produtividade (VTI/PO), pessoal ocupado (PO) e Valor de Trans- formação Industrial (VTI)}

Considerando as variáveis tratadas - produtividade, pessoal ocupado e valor da transformação industrial - por intensidade tecnológica, espera-se ter uma visão de conjunto da estrutura industrial de Santa Catarina. Segundo a Tabela 4, o segmento de média alta intensidade tecnológica, considerado o segmento mais produtivo, detêm na média dos triênios $21 \%$ do VTI e $17 \%$ do PO, conforme a Tabela 4. Isso significa que apenas $17 \%$ do pessoal ocupado de Santa Catarina estão em postos de trabalho de alta produtividade, e teoricamente obtendo melhores remunerações pelo exercício de suas funções.

Por sua vez, o segmento de baixa intensidade tecnológica, considerado o menos produtivo, é o que tem mais participação na transformação industrial, VTI. No triênio 2007 - 2009, 54\% do VTI total provêm de segmento de reduzida intensidade tecnológica. Tal segmento também emprega a maioria dos trabalhadores de Santa Catarina, chegando a ocupar neste triênio, 61\% do total do pessoal ocupado do Estado.

O segmento de alta intensidade tecnológica, signatário de fabricantes de produtos de maior valor agregado, possui baixíssima participação no total do VTI e do PO estadual, 2\% ao longo dos triênios considerados, respectivamente. A produtividade deste segmento, por sua vez, oscila entre a segunda e a terceira posições entre os segmentos analisados por intensidade tecnológica, não demonstrando um perfil definido e nem trajetória de ascensão na matriz industrial de Santa Catarina. 
Carolina Silvestre Cândido • Silvio A. F. Cario • Henrique Cavalieri da Silva

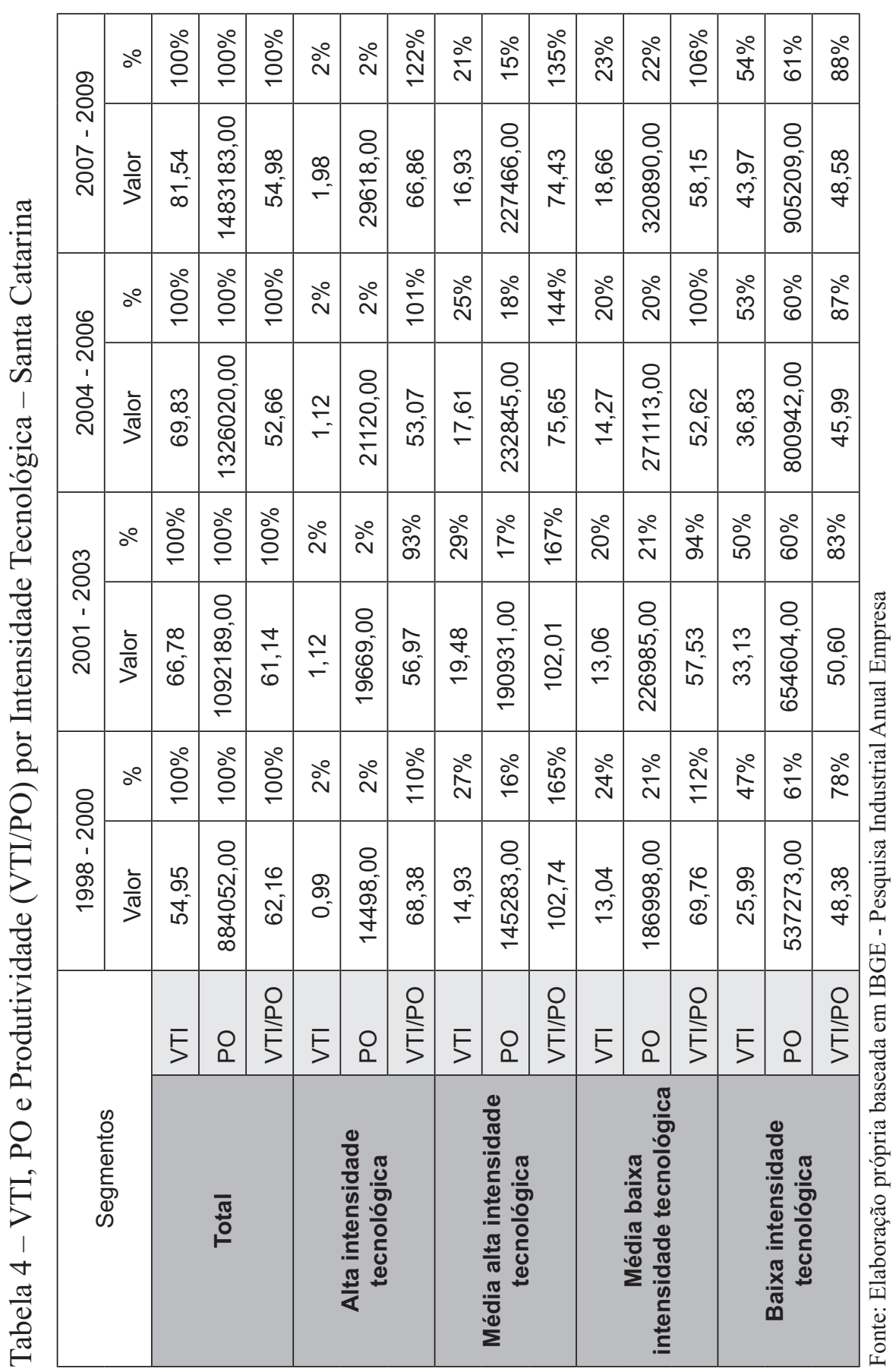


Tais valores constatam uma realidade da estrutura industrial de Santa Catarina, posta em termos da maioria do valor agregado nos produtos e dos trabalhadores empregados formalmente está alocada no segmento de menor produtividade, e assim de menores salários. Tal realidade não parece estar sendo alterada, ao menos não é vista nenhuma ruptura na série observada.

\section{5. À GUISA DA CONCLUSÃO}

Quando se analisa a conformação da estrutura industrial de países em desenvolvimento, dado o caráter tardio de seu estágio de expansão em relação aos países centrais, sempre está presente o debate sobre a heterogeneidade ou homogeneidade produtiva. O referencial analítico que expressa o pensamento de autores da CEPAL alerta que a existência de heterogeneidade estrutural decorre do atraso na criação e difusão do progresso técnico, que se mostra distinto, não somente entre a periferia e o centro, como também dentro dos espaços nacionais. Nos espaços domésticos, há setores que alcançam níveis elevados de produtividade por força do progresso técnico, e outros que não conseguem tal virtuosidade. Nos termos deste referencial, o aumento da produtividade do trabalho resulta em elevação da renda per-capita, logo, quanto menos heterogênea a estrutura produtiva, melhor o aproveitamento dos frutos do progresso técnico pela sociedade.

A existência de produtividade distinta resulta em divergências de renda, trazendo, por consequências, condições diferenciadas de vida para as pessoas residentes em determinado país. Logo, esforços devem se voltar em reduzir as brechas produtivas intersetores, e em última instância, reduzir a heterogeneidade produtiva, no propósito de se alcançar o desenvolvimento com equidade. Neste contexto, somente promover a industrialização por si só não basta, há insuficiência nesta proposição. Para promover o crescimento com equidade exige-se abrir a caixa preta do progresso técnico e adotar estratégia de potencializá-lo, de tal forma a superar a dependência e espalhar seu beneficio para o conjunto da sociedade. Nestes termos, seguindo os ensinamentos cepalinos, as ações devem se voltar em aumentar as capacitações tecnológicas e inovativas internas. 
Nestes termos, avaliar a estrutura produtiva industrial em nível estadual torna-se relevante, considerando que o setor industrial possui importante contribuição histórica na produção de riqueza. Esta inquietação torna-se primordial, considerando o desempenho deste setor ao longo dos últimos anos em Santa Catarina. De 2003 a 2008 este setor vem perdendo dinamismo, a exemplo do que está ocorrendo em nível nacional, considerando que a taxa de crescimento foi superior ao crescimento do PIB somente em 2004. Em outros termos, nos 6 anos de análise, somente em 1 ano, a taxa de crescimento produzida no setor industrial superou a taxa de crescimento do total produção de riqueza estadual. Este registro demonstra que a indústria tem perdido dinamismo e não tem puxado o crescimento econômico, sofrendo por consequência as agruras deste processo.

Sob este contexto, o presente trabalho avalia a existência de heterogeneidade industrial em Santa Catarina através da análise dos dados de sua matriz produtiva no período de 1998 a 2009. As variáveis VTI, PO e produtividade do trabalho, calculada como a proporção do VTI por pessoal ocupado, de acordo com a intensidade tecnológica, são objetos de análise. Os resultados apontam que a estrutura industrial apresenta heterogeneidade produtiva, cuja análise possibilita constatar sua reprodução ao longo do tempo, apresentando, portanto, caráter estrutural. Esta heterogeneidade produtiva reproduz níveis de agregação de valor distintos aos produtos, bem como apresenta diferentes níveis de produtividade do trabalho, por setor industrial.

Esta constatação é observada no nível do VTI. Enquanto indicador de quanto cada segmento industrial incorpora de valor ao produto, observa-se que em Santa Catarina, a maior representatividade cabe às indústrias figuradas no segmento de baixa intensidade tecnológica. Este segmento, em que estão presentes as indústrias de alimentos, bebidas e tabacos e têxteis, couro e calçados como os mais representativos, chega a alcançar próximo de 55\% de todo o VTI estadual. Ao agregar a este segmento também as indústrias de média baixa intensidade tecnológica, onde estão presentes as indústrias de borracha e produtos plásticos e produtos metálicos como as mais expressivas, alcança-se ao redor de $77 \%$ do valor adicionado total da produção industrial catarinense, no último ano de análise, 2009. 
Em relação ao PO na estrutura industrial de Santa Catarina, observa-se que o resultado se constitui uma reprodução da ocorrência com a magnitude do VTI estadual. Os segmentos de baixa e média baixa intensidades tecnológicas são responsáveis por aproximadamente $80 \%$ do pessoal registrado, formalmente, na estrutura industrial do Estado. As indústrias que compõem tais segmentos por intensidade tecnológica são intensiva em trabalho, comparativamente aos segmentos de média alta e alta tecnologia, por consequência, absorvem maior número de trabalhadores para o exercício de operações de intensidades tecnológicas reduzidas.

No tocante a produtividade do trabalho, considerado pela relação VTI/ PO, no propósito de apontar o quanto de agregação de valor se gera por pessoal ocupado em cada indústria, conclui-se que as maiores proporções ocorrem no segmento de indústria de média alta intensidade tecnológica. Este segmento é o que possibilita que os aumentos da produtividade gerem mais riqueza e encadeie a elevação na renda per capita, trazendo, por consequência, melhoria nas condições que propiciam bem estar às pessoas. Em verdade, neste segmento encontram-se indústrias que apresentam as melhores relações capital/trabalho, que expressam em aumento da produtividade com a mão-de-obra empregada. As principais indústrias componentes deste segmento intensivo de tecnologia são: máquinas e equipamentos elétricos; veículos automotores, reboques e semi-reboques; produtos químicos, exclusivo farmacêuticos; e, máquinas e equipamentos mecânicos. Apesar das indústrias citadas apresentarem melhores performance de produtividade, representam apenas $21 \%$ do VTI gerado na estrutura industrial catarinense, em 2007-2009.

Por fim, cabe salientar que ao longo da trajetória dos anos analisados, 1998-2009, não se constata sinais que apontem mudanças na evolução da produtividade do trabalho. A estrutura industrial continua sendo marcada pela forte presença das indústrias de baixa e média baixa tecnologias, com predomínio dos respectivos VTI e VPO sobre os demais segmentos. O predomínio destes segmentos dista dos de média alta e alta intensidade tecnológica, segmentos estes produtores e difusores do progresso técnico e portadores da matriz do paradigma tecnoprodutivo mundial em curso. 


\title{
STRUCTURAL HETEROGENEITY IN MANUFACTURING IN SANTA CATARINA: SOME EMPIRICAL EVIDENCE
}

\begin{abstract}
The objective of this research is studying the Brazilian and the state of Santa Catarina structural heterogeneity with the intent to contribute with studies about economic reality in this state. Economic theory presents structural heterogeneity as a result of uneven generation and diffusion of technical progress. It is expressed in the domestic production gap where, in the same production structure, developed productive strata with high levels of labour productivity coexist with archaic productive strata with reduced labour productivity. The existence of structural heterogeneity in the state of Santa Catarina industry is demonstrated through the analysis of the variables, industrial transformation value, employment, and labour productivity using the technology-intensity criteria, between 1998 and 2009.
\end{abstract}

Keywords: structural heterogeneity, state of Santa Catarina industry, labour productivity.

\section{REFERÊNCIAS}

BIELSCHOWSKY, Ricardo. Cinquenta anos de pensamentos na CEPAL: Uma resenha. In: BIELSCHOWSKY, Ricardo. Cinquenta anos de pensamento na CEPAL. Rio de Janeiro: Record, 2000. p. 13-68

CAMPOS, R. R. et all. Reestruturação industrial e aglomerações setoriais locais em Santa Catarina. In: VIEIRA, P. F. (org.) A pequena produção e o modelo catarinense de desenvolvimento. Florianópolis: APED Editora, 2002, p. 112-17.

CARNEIRO, R. Impasses do desenvolvimento brasileiro: a questão produtiva. Textos para Discussão, Campinas: IE/UNICAMP, n. 153, nov. 2008. 
CEPAL. Período de Sessões de Santo Domingo, 2008. Disponível em: $<$ http://www.eclac.org/cgi-bin/getProd.asp? xml=/prensa/noticias/comunicados/1/33141/P33141.xml\&xsl=/prensa/tpl-p/p6f.xsl\&base=/tpl-p/ top-bottom.xslt>. Acesso em: 20 out. 2011.

COUTINHO, L. A especialização regressiva: um balanço do desempenho industrial pós-estabilização. In: VELLOSO, J. P. R. (Org.). Brasil: desafios de um país em transformação. Rio de Janeiro: José Olympio, 1997.

FAJNZYLBER, Fernando. Industrialização na América Latina: da "caixa -preta" ao "conjunto-vazio". In: BIELSCHOWSKY, Ricardo. Cinquenta anos de pensamento na CEPAL. Rio de Janeiro: Record, 2000. p. 851-886.

FURTADO, Celso. Desenvolvimento e Subdesenvolvimento. Rio de Janeiro: Fundo de Cultura, 1961.

OREIRO, J. L.; FEIJÓ, C. A. Desindustrialização: conceituação, causas, efeitos e o caso b PREBISCH, Raúl. O Desenvolvimento Econômico da América latina e alguns de seus problemas principais. In: BIELSCHOWSKY, Ricardo. Cinquenta anos de pensamento na CEPAL. Rio de Janeiro: Record, 2000a. p. 69-136.

PREBISCH, R. O Desenvolvimento Econômico da América latina e alguns de seus problemas principais. In: BIELSCHOWSKY, Ricardo. Cinquenta anos de pensamento na CEPAL. Rio de Janeiro: Record, 2000a. p. 69-136.

PREBISCH, R. Por uma dinâmica do desenvolvimento latino-americano. In: BIELSCHOWSKY, Ricardo. Cinquenta anos de pensamento na CEPAL. Rio de Janeiro: Record, 2000b. p. 451-488.

RODRIGUEZ, O. Teoria do Subdesenvolvimento da CEPAL. Rio de Janeiro: Forense-universitária, 1981. 